\section{FIGHTING HUNGER IN THE TIME OF COVID-19: A QUALITY IMPROVEMENT PROJECT TO INCREASE SCREENING AND UTILIZATION OF FOOD RESOURCES}

Masouma Mohamed, Beenish Rubbab, Ana Cortez, Chelsea Lee, Courtney Port, Bann Alshamma. Inova Children's Hospital, USA

\subsection{6/bmjoq-2020-|HI.32}

Background The Food Research \& Action center (FRAC) and the American Academy of Pediatrics(AAP) define food insecurity as 'the limited or uncertain access to enough food.' A study done in 2018 found that 37 million (11.5\% ) of US households were food insecure. This number is expected to grow during the current pandemic of COVID 19 due to the rising unemployment rates and school closures. Food insecurity in children is associated with an increased rate of illness and hospitalization as well as increased risk of behavioral and

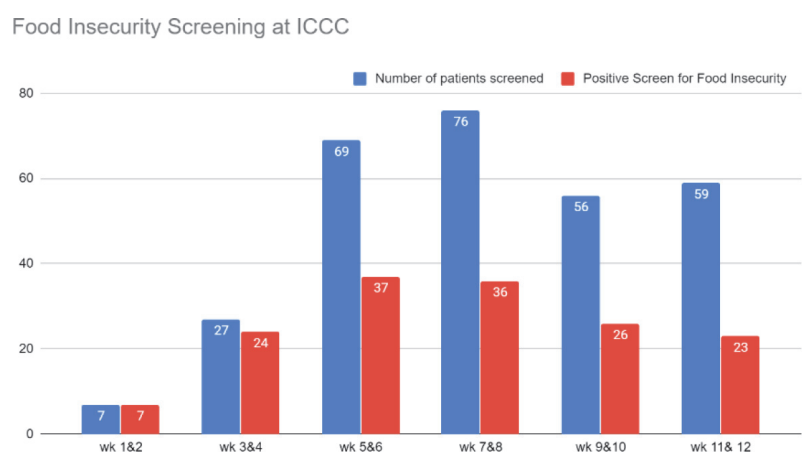

Abstract 32 Figure 1 Number of families screened for food insecurity

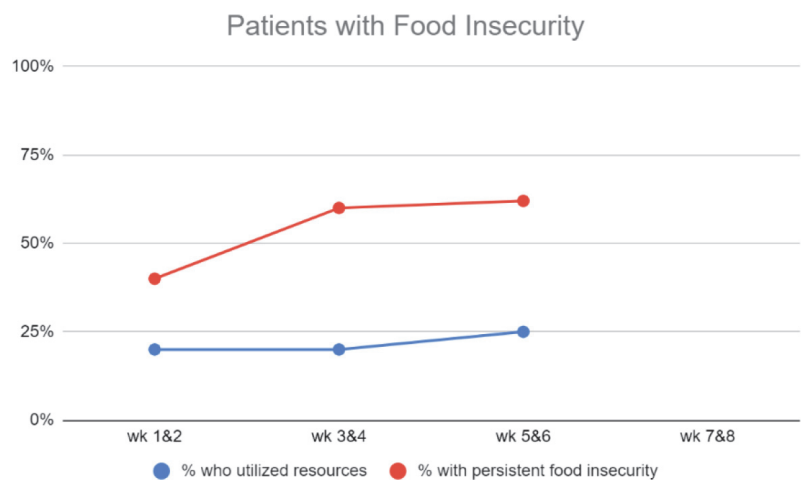

Abstract 32, Figure $2 \%$ of families screened for food insecurity and $\%$ of families screened positive

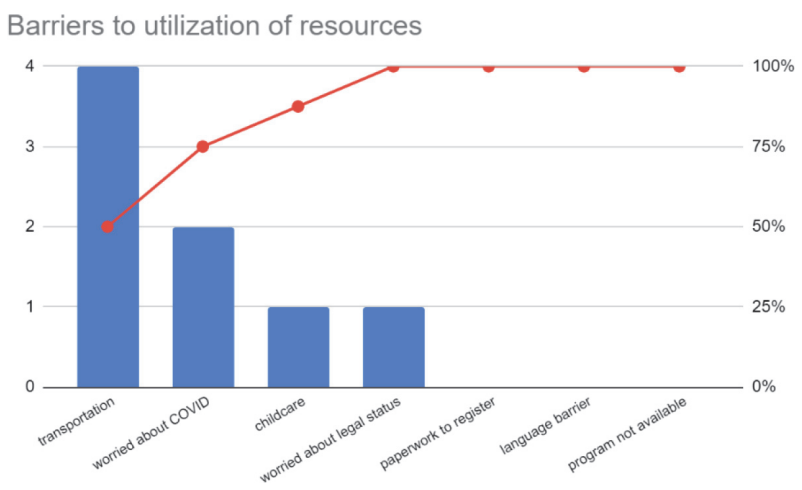

Abstract 32 Figure 3 Barriers to utilization of resources

emotional disorders. The APP recommends use of a validated screening tool at health maintenance visits to identify food insecure families.

Objectives Our project aims to increase the percentage of families screened for food insecurity and the utilization of food resources by $20 \%$ in 6 months. It takes place at a safety-net pediatric clinic, which acts as a medical home for children of low-income families on Medicaid or without insurance including undocumented children.

Methods The Model for Improvement and sequential PDSA cycles were utilized. Interventions included education for providers, creating a screening tool and implementing it into the patient visit workflow, a handout of food resources that can be used for in person or virtual patient visits. Outcome measures are the percentage of patients who utilize local food resources and the percentage of families remaining food insecure upon telephone follow-up. Process measure is the number of patients screened for food insecurity.

Results The highest number of families screened for food insecurity was 67 in one two weeks cycle (figures 1 and 2). Lack of transportation was the major barrier for accessing food resources (figure 3).

Conclusions Our next efforts will be aimed at overcoming barriers to resources that families face, adopting innovative ways to communicate with families and developing opportunities for community collaboration with food resources. 